Tropical Journal of Pharmaceutical Research, February 2009; 8 (1): 63-70

(c) Pharmacotherapy Group, Faculty of Pharmacy, University of Benin, Benin City, 300001 Nigeria.

All rights reserved.

Research Article

Available online at http://www.tjpr.org

\title{
Fast Dissolving Tablets of Aloe Vera Gel
}

\author{
Jyotsana Madan ${ }^{1}$, AK Sharma ${ }^{2}$, Ramnik Singh ${ }^{3}$ \\ ${ }^{1}$ UP Technical University, Lucknow, India, ${ }^{2}$ MJP Rohilkhand, University, Bareilly, India, ${ }^{3}$ Sri Sai College of Pharmacy, \\ Pathankot, India
}

\begin{abstract}
Purpose: The objective of this work was to prepare and evaluate fast dissolving tablets of the nutraceutical, freeze dried Aloe vera gel.

Methods: Fast dissolving tablets of the nutraceutical, freeze-dried Aloe vera gel, were prepared by dry granulation method. The tablets were evaluated for crushing strength, disintegration time, wetting time, friability, drug content and drug release. $A 3^{2}$ full factorial design was applied to investigate the combined effect of two formulation variables - amounts of microcrystalline cellulose and mannitol.

Results: The results of multiple regression analysis revealed that in order to obtain a fast dissolving tablet of the Aloe vera gel, an optimum concentration of mannitol and a higher content of microcrystalline cellulose should be used. A response surface plot was also provided to graphically represent the effect of the independent variables on the disintegration time and wetting time. The validity of the generated mathematical model was tested by preparing a check point batch.

Conclusion: This investigation has demonstrated that satisfactory fast dissolving Aloe vera gel tablets can be formulated. It also showed the potential of experimental design in understanding the effect of formulation variables on the quality of fast dissolving tablets.
\end{abstract}

Keywords: Aloe vera, Fast dissolving tablet, Factorial design, Mathematical model, Mannitol, Microcrystalline cellulose 


\section{INTRODUCTION}

The genus, Aloe, belongs to the family, Liliaceae, and includes the species Aloe barbadensis Miller, commercially known as Aloe vera. Aloe vera has been used therapeutically for many centuries and is of particular interest due to its lengthy historic reputation as a curative agent and its widespread use in supplementary therapies. Aloe gel is the colorless gel contained in the inner parts of the fresh leaves ${ }^{1}$. Chemical analysis has revealed that this clear gel contains amino acids, minerals, vitamins, enzymes, proteins, polysaccharides and biological stimulators. The Aloe vera gel, beginning in the 50 's, has gained recognition as a base for nutritional drinks and foods ${ }^{2-4}$, as a moisturizer, and a healing agent in cosmetics $^{5}$ and OTC drugs ${ }^{6}$.

Approximately one-third of the population, primarily, geriatric and pediatric populations, has swallowing difficulties, resulting in poor compliance with oral drug therapy ${ }^{7}$. Fast dissolving tablets offer the combined advantages of performance, convenience, rapid onset of action and patient compliance and allow administration of an oral solid dose form in the absence of water or fluid intake ${ }^{8}$. When placed on the tongue, it disintegrates instantaneously, releasing the drug which dissolves or disperses in the saliva ${ }^{9}$. They are prepared by techniques such as tablet molding, spray drying, lyophilization, sublimation, or addition of disintegrants ${ }^{10}$. Pharmaceutical formulators often face the challenge of finding the right combination of formulation variables that will produce a product with optimum properties. This study was undertaken to formulate a suitable fast dissolving nutraceutical tablet of freeze dried aloe vera gel (AVG), utilizing factorial design.

\section{MATERIALS AND METHODS}

\section{Plant material}

A. vera plants were collected (March 2003) and authenticated by Dr. C.S. Pandey of
Medicinal Plant Research and Development Centre, Govind Pant University of Agriculture and Technology, Pantnagar (Uttarakhand), India. A voucher specimen (AV-8) was retained in our museum for future reference.

\section{Other materials}

Croscarmellose sodium (CCS), crospovidone (CLP) and sodium starch glycolate (SSG) were purchased from S.D. Fine Chem., Mumbai, India. Microcrystalline cellulose Avicel $\mathrm{PH} 101$ - hereinafter referred to as MCC, was procured from FMC Corporation, Philadelphia, USA. Mannitol was purchased from Merck India Ltd, Mumbai, India. Anhydrous lactose, talc, magnesium stearate and hydrochloric acid were obtained from $\mathrm{CDH}$ Chemicals, Delhi, India. Congo red reagent and methylene blue were acquired from Nice Chemicals Pvt. Ltd, Cochin, India.

\section{Preparation of freeze-dried Aloe vera gel (AVG)}

The inner mucilaginous parenchymatous tissues of leaves of Aloe vera plants were separated out with the help of a sterile knife. and homogenized in a blender (National blender, Matushita Co. Japan) at $30 \mathrm{rpm}$. The homogenized mass was separated with a G3 sintered glass filter under vacuum, freezedried using a bench-top freeze-dryer (MC 2L, Cyberlab, USA) and subsequently stored at $4^{0} \mathrm{C}{ }^{11}$. The ratio of AVG to lyophilized powder was 200:1.

\section{Preparation of AVG tablets}

A preliminary screening of the disintegrants croscarmellose sodium (CCS), crospovidone (CLP), sodium starch glycolate (SSG) and microcrystalline cellulose (MCC) - was conducted. Mannitol was incorporated as a soluble filler to improve palatability, impart a cooling sensation and sweet taste upon dissolution. Granulation was carried out by the dry granulation technique. All the ingredients were compressed and slugs of $0.8 \mathrm{~g}$ were produced at a compression force of $22.0 \pm 1.0$ 
$\mathrm{kN}$ using flat faced tooling $17 \mathrm{~mm}$ in diameter on a single punch tablet machine (Cadmach Machinery Ltd., Ahmedabad, India).

The slugs were then milled and the resulting granules sieved through sieve no. 20 USP. The granules were further mixed with a glidant-lubricant blend containing magnesium stearate $(1 \% \mathrm{w} / \mathrm{w})$ and talc $(2 \% \mathrm{w} / \mathrm{w})$. The granules were compressed using a single punch tablet machine (Cadmach Machinery Ltd., Ahmedabad, India) fitted with $8 \mathrm{~mm}$ round standard concave punches. The tablet thickness was about $4.56 \pm 0.06 \mathrm{~mm}$.

\section{Evaluation of the tablets}

\section{Hardness test}

The crushing strength of the tablets $(n=5)$ was measured using a Monsanto hardness tester (Sheetal Scientific industries, Mumbai, India).

\section{Friability test}

The friability of a sample of 20 tablets was measured using a Roche Friabilator (Electrolab, India). Twenty preweighed tablets were rotated at $25 \mathrm{rpm}$ for $4 \mathrm{~min}$. The tablet were then reweighed after removal of fines and the percentage of weight loss was calculated.

\section{Wetting time}

The wetting time of the tablets $(n=6)$ was measured using a modified procedure described by Gohel et $\mathrm{al}^{12}$. Five circular tissue papers ( Dexina tissues, Gujarat, India) of 10 $\mathrm{cm}$ diameter were placed in a Petri dish (internal diameter $10 \mathrm{~cm})$. Water $(10 \mathrm{~mL}$ ) containing methylene blue $(10 \% \mathrm{w} / \mathrm{v})$, a water soluble dye, was added to the Petri dish. A tablet was carefully placed in the centre of the Petri dish and the time taken for the water to reach the upper surface of the tablets was noted as wetting time.

\section{Disintegration time}

This test was performed on 6 tablets. For disintegration time, one tablet was placed in the centre of the Petri dish (internal diameter $10 \mathrm{~cm}$ ) containing $10 \mathrm{ml}$ of water and the time taken by the tablet to disintegrate completely was noted ${ }^{12}$.

\section{Drug content uniformity}

Colorimetric measurement of glucomannan in the AVG was used for determining drug content uniformity ${ }^{13}$. For the drug content, 10 tablets were weighed and triturated. A tablet triturate, equivalent to $2 \mathrm{mg}$ of $\mathrm{AVG}$, was weighed accurately and dissolved in $100 \mathrm{ml}$ of distilled water and filtered. From this solution, $0.4 \mathrm{ml}$ was transferred to a $10 \mathrm{ml}$ test tube. To this, $4 \mathrm{ml}$ of Congo red reagent $(0.01 \%)$ was added with mild vortexing. The mixture was left at room temperature for $20 \mathrm{~min}$ and absorbance was measured at $540 \mathrm{~nm}$ wavelength using UV-VIS spectrophotometer (SL-196, Elico Ltd). The amount of glucomannan was calculated by interpolating from the standard curve $\left(r^{2}=0.9747\right)$.

\section{Dissolution studies}

The in vitro dissolution study was carried out in a USP dissolution test apparatus (TDT-OP Electrolab, Mumbai India), type 2 (paddle) with a dissolution media of $900 \mathrm{~mL}$ of $0.1 \mathrm{M}$ hydrochloric acid at $50 \mathrm{rpm}\left(37^{\circ} \mathrm{C} \pm 0.5^{\circ} \mathrm{C}\right)$. Samples $(n=6)$ were withdrawn at the end of $30 \mathrm{~min}$ and the dissolution of drug was expressed as percent drug dissolved at the end of $30 \mathrm{~min}^{14}$.

\section{Full factorial design}

A $3^{2}$ randomised factorial design was adopted to optimize the variables. In this design, two factors were evaluated each at 3 levels and experimental trials were performed at all 9 possible combinations ${ }^{15}$. The amount of disintegrant (MCC) and the soluble filler (mannitol) were chosen as independent variables. The disintegration time and wetting 
time were selected as the dependent variables. The formulation and evaluation of factorial batches ( $F 1$ to $F 9$ ) is shown in Table 2. The following statistical model incorporating interactive and polynomial terms was used to evaluate the responses:

$Y=b_{0}+b_{1} X_{1}+b_{2} X_{2}+b_{12} X_{1} X_{2}+b_{11} X_{1}^{2}+b_{22} X_{2}^{2}$

where $Y$ is the dependent variable, $b_{0}$ is the arithmetic mean response of the 9 runs, and $b_{1}$ and $b_{2}$ are the estimated coefficients for the factors $X_{1}$ and $X_{2}$ respectively.

The main effects $\left(X_{1}\right.$ and $\left.X_{2}\right)$ represent the average result of changing 1 factor at a time from its low to high value. The interaction

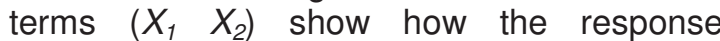
changes when 2 factors are simultaneously changed. The polynomial terms $\left(X_{1}{ }^{2}\right.$ and $\left.X_{2}{ }^{2}\right)$ are included to investigate nonlinearity. The multiple regression analysis was performed followed by ANOVA to identify insignificant variables.

\section{RESULTS}

Hardness of the tablets was in the acceptable range of 2.56 to $3.55 \mathrm{~kg} / \mathrm{cm}^{2}$. Friability was 0.51 to $0.82 \%$. Drug content and release were $100 \pm 5 \%$ and $82.6-88.4 \%$, respectively. The results of the prelimnary studies (Table 1 ) revealed that the tablets containing microcrystalline cellulose (MCC) exhibited rapid disintegration and wetting followed by tablets containing croscarmellose sodium (CCS), crospovidone (CLP), sodium starch glycolate (SSG) in that order.

\section{Factorial design}

The amount of disintegrant (MCC, $\mathrm{X}_{1}$ ) and the soluble filler (mannitol, $X_{2}$ ) were chosen as independent variables in a $3^{2}$ full factorial design. The disintegration time and wetting time were selected as the dependent variables. The data (Table 2) clearly indicates that disintegration time and wetting time are strongly dependent on the selected independent variables. The fitted equations (full and reduced) relating the responses, disintegration time and wetting time, to the transformed factor are shown in Table 3.

\section{DISCUSSION}

\section{Preliminary trials}

In order to select the best disintegrant, four disintegrants were studied in preliminary trials. The efficiency of disintegrants can be affected in varying magnitudes by the presence of a soluble filler in the tablet formulations ${ }^{16}$. This is expected due to the fact that the quantity of water penetrating into the tablet bed is limited. The soluble filler (mannitol) has good aqueous solubility, negative heat of solution and good wetting properties ${ }^{17}$. Mannitol will consume water partially, leaving only a part of the total water to penetrate into the tablet for the development of force necessary for disintegration. The results of the preliminary studies (Table 1 ) revealed that the tablets containing microcrystalline cellulose (MCC) exhibited rapid disintegration and wetting. MCC has good wicking and absorbing capacities $^{18}$. Tablets of MCC disintegrated rapidly due to the rapid passage of water into the tablets resulting in the instantaneous rupture of the hydrogen bonds ${ }^{19}$. The delayed disintegration and wetting time of the tablets formulated using other disintegrants could be attributed to their slow water uptake and high gelling tendency. Based on the results of the preliminary study, MCC was selected as the disintegrant for further studies. The optimum concentration of MCC may be less than $12 \%$.

\section{Factorial design}

The polynomial equations can be used to draw conclusions after considering the magnitude of coefficient and the mathematical sign it carries (i.e., positive or negative). Table 4 shows the results of the analysis of variance (ANOVA), which was performed to identify insignificant factors. The high values of correlation coefficient for disintegration time and wetting time (Table 4) indicate a good fit. The equations may be used to obtain estimates of the response as a small error of variance was noticed in the replicates ${ }^{20}$. 
Table 1: Tablet formulation and evaluation of preliminary trials*

\begin{tabular}{lllll}
\hline Ingredient & \multicolumn{5}{c}{ Batch code } \\
& A1 & A2 & A3 & A4 \\
\hline Freeze dried aloe vera gel (mg) & 150 & 150 & 150 & 150 \\
Microcrystalline cellulose (mg) & 25 & - & - & - \\
Croscarmellose sodium (mg) & - & 25 & - & - \\
Sodium starch glycolate (mg) & - & - & 25 & - \\
Crospovidone (mg) & - & - & - & 25 \\
Mannitol (mg) & 150 & 150 & 150 & 150 \\
Anhydrous lactose q .s to---(mg) & 400 & 400 & 400 & 400 \\
Disintegration time (sec) & 36.5 & 41.8 & 49.2 & 45.6 \\
Wetting time (sec) & 32.5 & 36.8 & 43.6 & 39.4 \\
Hardness (Kg/cm $\left.{ }^{2}\right)$ & 3.55 & 3.24 & 2.56 & 2.96 \\
Friability (\% loss) & 0.56 & 0.76 & 0.82 & 0.83 \\
Drug content(\%) & 99.5 & 100.4 & 98.3 & 96.7 \\
(\%) Release & 88.4 & 87.3 & 82.6 & 85.3 \\
\hline
\end{tabular}

${ }^{*} A l l$ batches contained $2 \% w / w$ talc and $1 \% w / w$ magnesium stearate.

Table 2: $3^{2}$ Full factorial design layout*

\begin{tabular}{|c|c|c|c|c|}
\hline \multirow[t]{2}{*}{ Batch code } & \multicolumn{2}{|c|}{$\begin{array}{l}\text { Variable levels in coded form } \\
\text { time }\end{array}$} & Disintegration time & Wetting \\
\hline & $\mathbf{X}_{1}(\mathrm{mg})$ & $\mathbf{X}_{2}(\mathrm{mg})$ & \pm SD $(\mathrm{sec})$ & $\pm \mathrm{SD}(\mathrm{sec})$ \\
\hline F1 & -1 & +1 & $36.75 \pm 2.25$ & $34.20 \pm 0.75$ \\
\hline $\mathrm{F} 2$ & 0 & +1 & $36.33 \pm 1.85$ & $32.40 \pm 1.08$ \\
\hline F3 & +1 & +1 & $35.45 \pm 3.32$ & $32.66 \pm 1.87$ \\
\hline F4 & -1 & 0 & $34.55 \pm 3.12$ & $30.54 \pm 0.63$ \\
\hline F5 & 0 & 0 & $34.00 \pm 1.33$ & $29.89 \pm 1.23$ \\
\hline F6 & +1 & 0 & $33.24 \pm 1.53$ & $29.62 \pm 0.89$ \\
\hline F7 & -1 & -1 & $34.23 \pm 2.45$ & $31.66 \pm 0.66$ \\
\hline F8 & 0 & -1 & $34.40 \pm 4.23$ & $30.90 \pm 0.76$ \\
\hline F9 & +1 & -1 & $34.14 \pm 1.88$ & $30.00 \pm 1.23$ \\
\hline \multirow[t]{2}{*}{ Check point } & +0.8 & -0.2 & 33.6 & 29.2 \\
\hline & \multicolumn{4}{|c|}{ Actual values } \\
\hline Coded values & & $\mathrm{X}_{1}$ & & $\mathbf{X}_{2}$ \\
\hline-1 & & 10 & & 100 \\
\hline 0 & & 20 & & 150 \\
\hline 1 & & 30 & & 200 \\
\hline
\end{tabular}

${ }^{*}$ All batches contained $150 \mathrm{mg}$ AVG, 2\%w/w talc, $1 \% \mathrm{w} / \mathrm{w}$ magnesium stearate.

$X_{1}$ indicates amount of $M C C(\mathrm{mg}) ; X_{2}$ is amount of mannitol $(\mathrm{mg}) ; S D=$ standard deviation.

\section{Full and reduced models}

The significance level of coefficients, $b_{12}$ and $b_{11}$, were found to be more than 0.05 , hence they were omitted from the full model to generate the reduced model. The results of statistical analysis are shown in Table 3 . The coefficients, $b_{1}, b_{2}$ and $b_{22}$, were found to be significant at $\mathrm{P}<0.05$; hence they were retained in the reduced model. The reduced model was tested in portions to determine whether the coefficient $b_{12}$ and $b_{11}$ contributed significant information for the prediction of both disintegration time and wetting time. The results for the test of the model in portions are shown in Table 4. F-Statistics of the results of 
Table 3: Summary of results of regression analysis*

\begin{tabular}{lllllll}
\hline \multicolumn{7}{c}{ For disintegration time } \\
\hline $\begin{array}{l}\text { Response (disintegration } \\
\text { time) }\end{array}$ & $\mathrm{b}_{0}$ & $\mathrm{~b}_{1}$ & $\mathrm{~b}_{2}$ & $\mathrm{~b}_{12}$ & $\mathrm{~b}_{11}$ & $\mathrm{~b}_{22}$ \\
\hline FM & \multicolumn{7}{c}{$\begin{array}{l}34.052 \\
\text { RM }\end{array}$} & -0.450 & 0.960 & -0.183 & -0.303 & 1.287 \\
& 33.930 & -0.450 & 0.960 & - & - & 1.287 \\
\hline \multicolumn{7}{c}{ For wetting time } \\
\hline Response (Wetting time) & $\mathrm{b}_{0}$ & $\mathrm{~b}_{1}$ & $\mathrm{~b}_{2}$ & $\mathrm{~b}_{12}$ & $\mathrm{~b}_{11}$ & $\mathrm{~b}_{22}$ \\
\hline FM & 29.761 & -0.687 & 1.117 & 0.383 & 0.0300 & 1.953 \\
RM & 30.017 & -0.687 & 1.117 & - & - & 1.953 \\
\hline
\end{tabular}

${ }^{*}$ FM indicates full model; and RM, reduced model

Table 4: Calculations for testing the model in portions*

\begin{tabular}{|c|c|c|c|c|c|c|}
\hline \multicolumn{7}{|c|}{ For disintegration time } \\
\hline & DF & SS & MS & $\mathbf{F}$ & $\mathbf{R}^{2}$ & \multirow{7}{*}{$\begin{array}{l}\text { Fcalc }=4.920 \\
\text { Ftable }=9.55 \\
\text { DF }=(2,3)\end{array}$} \\
\hline \multicolumn{6}{|c|}{ Regression } & \\
\hline FM & 5 & 10.489 & 2.098 & 47.574 & 0.988 & \\
\hline RM & 3 & 10.056 & 3.352 & 29.635 & 0.947 & \\
\hline \multicolumn{6}{|c|}{ Error } & \\
\hline $\mathrm{FM}$ & 3 & 0.132 & 0.0441 & & & \\
\hline $\mathrm{RM}$ & 5 & 0.566 & 0.113 & & & \\
\hline \multicolumn{7}{|c|}{ For wetting time } \\
\hline & DF & SS & MS & $\mathbf{F}$ & $\mathbf{R}^{2}$ & \multirow{7}{*}{$\begin{array}{l}\text { Fcalc }=0.198 \\
\text { Ftable }=9.55 \\
\text { DF }=(2,3)\end{array}$} \\
\hline \multicolumn{6}{|c|}{ Regression } & \\
\hline $\mathrm{FM}$ & 5 & 18.239 & 3.648 & 18.397 & 0.968 & \\
\hline $\mathrm{RM}$ & 3 & 17.942 & 5.981 & 33.511 & 0.953 & \\
\hline \multicolumn{6}{|c|}{ Error } & \\
\hline $\mathrm{FM}$ & 3 & 0.595 & 0.198 & & & \\
\hline $\mathrm{RM}$ & 5 & 0.892 & 0.178 & & & \\
\hline
\end{tabular}

${ }^{*} D F$ indicates: degrees of freedom; SS, sum of squares; MS, mean of squares; F, Fischer's ratio; $R^{2}$, regression coefficient; $F M$, full model; and $R M$, reduced model.

ANOVA of full and reduced model confirmed omission of non-significant terms of equation 1. Since the calculated value (4.92 and 0.198 ) is less than the tabulated value $(9.55, \alpha=0.05$, df 2,3), it may be concluded that the interaction terms $b_{12}$ and the polynomial term $b_{11}$ do not contribute significantly to the prediction of both disintegration time and wetting time and, therefore, can be omitted from the full model. The results of multiple linear regression analysis (reduced model) show that for both disintegration time and wetting time, the amount of $\operatorname{MCC}\left(X_{1}\right)$ had a negative effect while the concentration of mannitol $\left(X_{2}\right)$ had a positive effect. It means that as the amount of MCC is increased, both the disintegration time and wetting time decreases, while as the amount of mannitol is increased both the disintegration time and wetting time would increase. Therefore, a high level of MCC and low level of mannitol should be selected for the rapid disintegration of the 
tablets. The relationship between the dependent and independent variables was further elucidated using surface response plots. The data of the response surface plot (Figures 1 and 2)) demonstrate that both $X_{1}$ and $X_{2}$ affect the disintegration and wetting times. Based on the foregoing, discussion batch F6 (disintegration time: $33.24 \mathrm{sec}$ and wetting time: $29.62 \mathrm{sec}$ ) was selected as a promising batch. A checkpoint batch was prepared at $X_{1}=+0.8$ level and $X_{2}=-0.2$ level. The values of disintegration and wetting times expected from the reduced model for this batch are 33.78 and $29.32 \mathrm{sec}$, respectively. Table 2 indicates the results were as expected. Thus, the statistical model is mathematically valid.

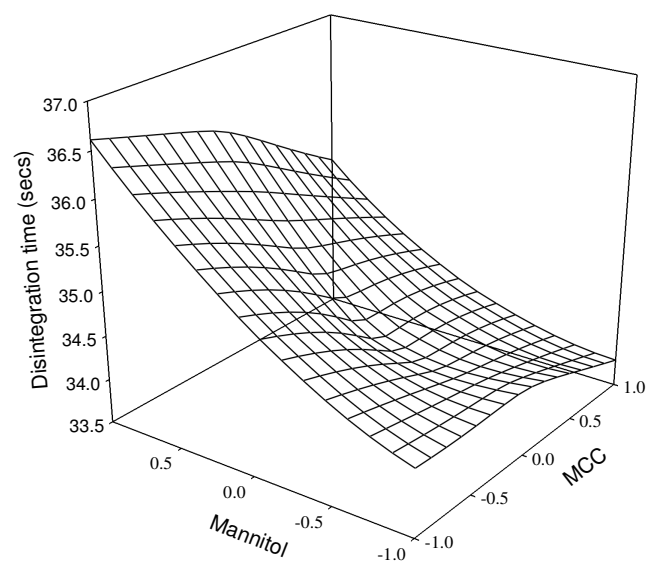

Figure 1: Response surface plot for disintegration time

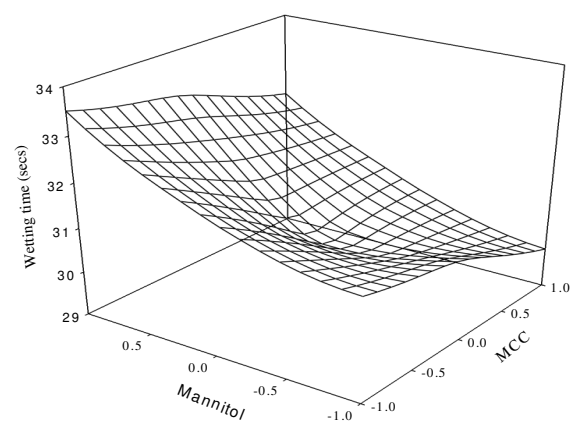

Figure 2: Response surface plot for wetting time

\section{CONCLUSION}

The results of a $3^{2}$ full factorial design revealed that the amount of microcrystalline cellulose and mannitol significantly affect the dependent variables - disintegration and wetting times. The present study has revealed the feasibility of optimization procedure in developing AVG fast dissolving tablets.

\section{REFERENCES}

1. Grindlay $D$, Reynolds $T$. The Aloe vera phenomenon: $A$ review of the properties and modern uses of the leaf parenchyma gel. J Ethnopharmacol,1986; 116:117-151.

2. Eshun $\mathrm{K}, \mathrm{He} Q$. Aloe vera: a valuable ingredient for the food, pharmaceutical and cosmetic industries-a review. Crit Rev Food Sci Nutr,2004 ; 44 : 9196.

3. Atherton P. Aloe vera: magic or medicine?. Nurs Stand, $1998 ; 41: 49-54$.

4. Vogler B K, Ernst E. Aloe vera: a systematic review of its clinical effectiveness. Br J Gen Pract. 1999; 49 :823-828.

5. Reynolds T, Dweck AC. Aloe vera leaf gel: a review update. J Ethnopharmacol, 1999; 68 : 3-37.

6. Shelton RM. Aloe vera. Its chemical and therapeutic properties. Int J Dermatol, 1991; 30: 679-683.

7. Seager H. Drug delivery products and the zydis fast dissolving dosage forms. J Pharm Pharmacol, 1998; $50: 375-382$.

8. Reddy LH, Ghosh B, Rajneesh. Fast dissolving drug delivery systems: a review of the literature. Indian J Pharm Sci, 2002; 64 : 331-336.

9. Biradar SS, Bhagavati S T , Kuppasad I J . Fast dissolving drug delivery systems: A brief overview. Internet J Pharmacol, 2006; 4(2).

10. Chang R, Guo X, Burnside B, Couch R. A review of fast dissolving tablets. Pharm Technol, 2000 ; 24: 52-58.

11. Turner $C E$, Williamson $D A$, Stroud $P A$, Talley $D J$. Evaluation and comparison of commercially available Aloe vera $L$. products using size exclusion chromatography with refractive index and multi-angle laser light scattering detection. Int Immunopharmacol, 2004 ; 4:1727-1737.

12. Gohel M, Patel M, Amin A, Agarwal R, Dave R, Bariya N. Formulation design and optimization of mouth dissolve tablets of nimesulide using vacuum drying technique. AAPS. Pharm.Sci.Tech, 2004 ; 5(3): E36.

13. Eberendu AR, Luta G, Edwards JA, McAnalley BH, Davis $B$, Rodriguez S, Henry CR. Quantitative colorimetric analysis of aloe polysaccharides as a 
measure of Aloe vera quality in commercial products. J AOAC Int, 2005 ; 88: 684-691.

14. Patel DM, Patel M M. Optimization of Fast dissolving Etoricoxib tablets prepared by sublimation technique. Indian J Pharm Sci, 2008 ; 70: 71-76.

15. Bolton S. Pharmaceutical Statistics. Ed 3, New York; Marcel Decker Inc. 1990, pp 234-236.

16. Bolhuis GK, Zuurman K, Te Wierik GHP. Improvement of dissolution of poorly soluble drugs by solid deposition on a super disintegrant. II. The choice of super disintegrants and effect of granulation. Eur J Pharm Sci, 1997; 5: 63-69.

17. Kizumi K, Watanabe $Y$, Morita K, Utoguchi N, Matsumoto M. New method of preparing high porosity saliva soluble compressed tablets using mannitol with camphor. Int J Pharm, 1997; 152 :127-131.

18. Patel VF, Patel N M. Statistical evaluation of influence of viscosity of polymer and types of filler on dipyridamole release from floating matrix tablets. Indian J Pharm Sci, 2007; 69: 51-57.

19. Jacob $S$, Shirwaikar $A A$, Joseph $A$, Srinivasan KK. Novel co-processed excipients of mannitol and microcrystalline cellulose for preparing fast dissolving tablets of glipizide. Indian J Pharm Sci, 2007; 69: 633-639.

20. Sammour OA, Hammad MA, Megrab NA, Zidan AS. Formulation and optimization of mouth dissolve tablets containing Rofecoxib solid dispersion. AAPST.,2006;7: E55. 